\title{
Study on Industrialization Prospects of the Silk Road Tea Culture
}

\author{
Yan Xiao ${ }^{1, a}$, Zhaoyu Liao ${ }^{1, b}$ \\ ${ }^{1}$ School of economics and management, Tarim University, Xinjiang, 843000 \\ ${ }^{\mathrm{a}}$ email, ${ }^{\mathrm{b}}$ email
}

Keywords: Industrial prospects; The Silk Road; Tea Culture

\begin{abstract}
Since ancient times, tea is the origin of Chinese Silk Road, is related to the national and regional economic and trade exchanges and is an important commodity, tea culture is major carriers to spread Chinese civilization to the world. Let the tea culture along the ancient "Silk Road" and the spread of the Maritime Silk Road has become an industry, in line with the objective requirements of the tea culture of their own development, but also with the connotation of the second working conference spirit of Xinjiang high degree and open a bright future for the development and prosperity of southern Xinjing tea culture. It laid the foundation for development and social progress of the southern industry in Xinjiang.
\end{abstract}

\section{Introduction}

The cultural industry is recognized by the international community and one of the most promising growth potential of the industry in the 21st century, with the rapid development of Chinese economy, people's constant pursuit of material life, the rich spiritual and cultural life is increasingly becoming the ardent desire of our people the development of cultural industry is imperative. [1] Since the central work conference held in Xinjiang, Xinjiang take modern culture as a major strategic choice to lead the express train will elevate culture to an unprecedented height of strategic development in recent years, the introduction of policies in Xinjiang, financial support, base demonstration, exhibition promotion, cultural industries in Xinjiang water from the wind, the new formats are emerging. [2] At the same time, (2015) Third Silk Road in Xinjiang Cultural and Creative Industry Expo main push "Culture +" and "a guest" of the Silk Road culture theme, pushing industrial development in Xinjiang culture. In the study we found that the ages of the Chinese tea culture and tea industry development are inseparable, tea industry needs precipitated tea culture, tea culture, heritage and the development of the Silk Road tea industry depends on the rise and progress.

Since the Han Dynasty 2100 years ago, he was transported to the Central Plains tea Xinjiang, the local food culture of continuous integration, locals slowly began to accept and use, and finally it became indispensable Xinjiang locals drink in " Evolution of tea-horse trade, "" tea-horse Road "," brick tea trade "like, black tea, green tea, white tea, black tea and other large items pathway Xinjiang exported abroad, but also by the local people and become accepted Xinjiang diet an integral part of culture. Although many people believe that Xinjiang tea supplied by the Central Plains. Indeed, the tea produced in Xinjiang, now black jade tea roses, chrysanthemum tea Tianshan snow, along the Tarim Apocynum tea, willow tea.

Silk Road Tea Industry research is based on national cultural values "along the way" implementation of the strategy paper based southern geographical advantages, to provide financial explore the Silk Road Economic Belt, cultural communication, policy research, conflict prevention and the elimination of barriers established. [2] Currently, the Corps is in a new starting point, the role of the stabilizer, the melting pot, to further enhance the demonstration area, the fundamental position of agriculture in the further consolidation of the development process of new industrialization has accelerated noticeably, becoming a leading industrial revitalization , along with the rapid rise of the tertiary industry. Especially submitted a second central Xinjiang symposium and the state "along the way" strategy, so that the development of the Corps is facing unprecedented opportunities and challenges. Alar City in southern Xinjiang a division that works to promote the 
Silk Road Economic Belt core area of construction, the building is intended to become the Corps Alar agricultural demonstration zone, the core area of the Silk Road economic belt an important logistics node area "along the way" westward strategy hub, the implementation of the measures and preferential policies in Xinjiang to southern tea culture industry brings hope for tomorrow.

\section{The Silk Road Tea Industry Research Purpose and Significance of Cultural Values}

Southern tea is rich in resources, but the lack of good industrial environment, the lack of cultural connotation, supporting infrastructure lag, the industrialization of uncertainty in the development and utilization of tea cultural values still in the primary stage [3], how to enhance wire level road tea culture, accelerate the pace of development of cultural industries, in-depth fundamental research I Silk Road tea cultural values, cultural development of the industry, from the experience of other domestic tea cultural industry in developed regions of the Silk Road tea culture development Status Quo performed to collate and summarize, in order to provide new ideas and insights for the development of tea culture and tea culture for the industrial prospects Research modest contribution.

In this paper, choose "along the way" the context of development of the industrial prospects of tea cultural value of this study was performed by the local history of southern Now understand, I learned a Silk Road city of Alar City, is silk an important stopover on the way, but also the three hundred fifty-nine spirit of Western culture, the Silk road culture, Kunlun culture, the 359th brigade to carry forward the culture, but also the maintenance of stability in South power emergency center. Reveal the full range of tea culture in the development of major significance in southern Xinjiang, to undertake the country "along the way" strategy, promote embody the "tea and the world" spirit, give full play to Xinjiang, "the core area of the Silk Road," History intersection status " showcasing the exchange and integration tea culture silk road, it will be possible to provide a theoretical basis for policy development for the purpose of reference and southern cultural prosperity and social economy.

This paper attempts to use the value of cultural industries mining and industrial prospects Theory Silk Road tea cultural values were analyzed. The use of the Silk Road culture, tea culture theory, the theory of development of cultural industries, cultural industries and other related theories tea, black tea, green tea, black tea Xinjiang Apocynum tea, tea, brick tea the status quo, cultural development, cultural values of different tea industrialization of benefits comprehensive system to analyze, highlight Alar City in southern Xinjiang geographical advantages, and the Silk Road tea culture industry prospects were analyzed, and cultural values by tea mining, rationalization proposals, to promote the development of tea culture and future industry in South industry development plan to link together to provide guidance.

First, the rise of the Silk Road tea culture, the economic belt along the Silk Road, many countries and regions, providing a set of trade, culture, tourism, religious, military and other multi-level exchanges and cooperation platform, helping to eliminate barriers and achieve common ground, promote interoperability. Secondly, through the Silk Road Tea Culture Industry in the development of large strategic context Corps south, help to provide a broader stage for the future development of Alar, make full use of the coordination function of the culture industry, improve the degree of social civilization, can provide more social interaction platform for idea exchange, communication and understanding, regulate behavior, resolve conflicts, it is conducive to building a harmonious society. To effectively implement the General Secretary Xi Jinping "Abe Xinjiang solid stabilizer, a melting pot of people of all nationalities unite, advanced productive forces and advanced culture demonstration zone" goal. Again, through the development of the Silk Road Tea Culture Industry to achieve multi-party coordination, to achieve aggregate industry, such as restaurants, teahouses, health club, tea culture, tourism and other cultural industries, the use of geographical advantages frontier organize various cultural exchange between China and exhibition, can further enhance the visibility of Alar city in southern Xinjiang, the reconstruction image of the city, especially to inject new vitality into the development of cultural industries. 


\section{Researches on Tea Culture Industry}

Domestic research on the Silk Road tea culture industry, including both the development process of tea culture in the development and value of the development status around the tea culture, including the study of the cultural industry policies and strategies, but also to tea industry case studies, brand promotion strategy and so on. Meanwhile, a group of experts for tea culture and tea industry conducted fruitful research, Xiong Bolin "Chinese tea to integrate into" along the way "to the building," Tao Dechen "research status of Chinese tea culture and scientific development," Yang Jiang Fan Li Min Rong "China tea industry research report," Gong Yongxin "Chinese tea industry to develop new theory" and "promote tea culture, promoting tea cultural industry," Xia Liangyu "On the choice of China tea culture industry development strategy", Luo Zhan nine "China tea industry in transition ", etc., from the geographical perspective elucidates the value and status of the Silk Road tea culture development of tea industry.

Currently Overseas Research on Tea Culture Industry is mainly concentrated in the UK, Japan, Korea, etc., of their research on the tea more focused on drinking diet culture, for the comprehensive development of tea cultural industry, the value of mining use, comprehensive benefits realization aspect relates to less [4]. Such as: Wang Guilan "Japanese tea culture" in revealing the incoming Japanese tea and tea customs from China, in turn tea procedures and standardization, to explore its true essence. [5] Chen Qiuhong in "Comparison of the Japanese and Korean tea culture" in the analysis of whether it is tea culture connotation or extension are more, he is not limited to tea, tea, tea ceremony, tea culture also includes tea literature, tea art, tea art, folk tea culture and so on. Professor Wang Ren think from the Japanese tea ceremony can be attributed to the spirit of Zen, the mental state of heavy drinking when, Korean tea classified as Confucianism, focusing on norms, order and related etiquette. Chinese tea is more emphasis on taste, did not dare, production process atmosphere.

The 21st century is the era of the cultural economy, especially in developed countries, the cultural industry has become a leading national economy, under the influence of the Silk Road culture, Chinese tea and tea culture is also combined with the European social culture, the development of new tea culture form, such as South Korea's tea ceremony, Japanese tea ceremony, the British afternoon tea to Morocco, as the representative of the Arab world tea culture, ethnic, regional tea culture, rich in different countries and regions of people's material and cultural life, tea culture has become the content of life in many countries, citizens, and the development of tea industry model is relatively simple, based mainly in the spiritual pursuit.

\section{The Development Prospects of Tea Culture Industry}

With the rapid development of the information age, people are concerned about the Silk Road culture, more and more development and theoretical research on the Silk Road tea culture industry is also deepening, there are many issues that need to continue systematic research, the current , most of the domestic industry of the Silk Road tea culture Research descriptive record that describes the varieties of tea, tea sets and tea customs, which, on the Silk Road tea culture industry development of information is relatively simple [6]. For research Silk Road culture, just more than a dozen academic papers and scattered some tea culture works in the discourse mentioned. However, in terms of depth and breadth there is still insufficient, it can be said of the cultural values of the Silk Road tea extract or Industrial Prospect of academic research as well as a huge space.

Silk Road Tea Culture on the economic development of tea industry is playing an increasingly important role, along with in-depth study of tea culture, people will be more close to the actual tea culture industry, how to further identify the Silk Road Tea Culture Research the starting point will be closely integrated Silk Road tea culture tea culture Research and industrial economy up, the tea culture and tea trade combine to enhance the value of tea culture through injection, increase the economic benefits of tea industry, tea culture with function to play the effect of tea culture, tea culture made the industry to further promote the healthy development of tea industry [7], the study will also focus on development of tea industry in the field of "along the way" background. These 
provide some theoretical basis for the development of cultural industries in Xinjiang, but also more people are concerned about the cultural industry.

\section{Conclusion}

As a cultural phenomenon, silk road tea culture has very strong cultural influence and vitality, long-term presence in the community and development always affects people's production and spiritual lifestyle, that makes a harmonious balance of the development of society and continue to create a higher level of material and spiritual civilization. We can see that the integrated development of the cultural industry has become a trend, cultural force is to promote the industrialization of economic and social development of inner strength, southern tea culture should be part of the Silk Road cultural competitiveness, tea culture can develop into a item separate industry has some new ideas on the "culture +", "+ tea culture" to the development of other industries in southern socio-economic impact, the importance of clear Silk Road tea culture industry to local development, and thus tea Xinjiang cultural industry development and resource upgrades have a clear direction. This paper provides a reference for the government to develop the southern border region development plans and strategies and will also be the focus of research in the field of development of tea industry.

\section{Acknowledgements}

Tarim non-heritage cultural tourism Integrated Service System and Application (ID: 2013BAH27F00) National cultural and technological innovation projects

\section{References}

[1] Xiong Bolin. Chinese tea to integrate into "along the way" to the construction of [J]. Tea in the world, 2014, (7).

[2] Liao Zhaoyu. Western bibliography integration [D]. Tarim University, 2012.

[3] Xu Jialu. Wings spread Chinese culture --- about tea, tea, tea culture several conversations [J]. Chinese Television (record), 2014, (10).

[4] Yu Min, Wei Jian Chao. Liu Yan. Differences between China and Western tea culture [J]. Neijiang Teachers College, 2008, (23).

[5] Nan Yinshi. Inspiration Korean Cultural Industry Development Strategy of China [D]. Yanbian University, 2012.

[6] Gong Yongxin. Tea Cultural Industry Provement. Industrial Convergence [J]. Guangdong tea, 2009, (3).

[7] Deng Xianhui. Effective way actively explore the development of tea industry in [N]. Guizhou Daily, 2008-12-04. 